\title{
Effectiveness of a Need-Based Program in Relieving Psychological Distress of Family Caregivers of Leukemia Patients: A Randomized Clinical Trial
}

Mehrdad Abdullahzadeh ( $\sim$ mehrdad11012@gmail.com )

Islamic Azad University of Khorasgan Nursing and Midwifery Faculty https://orcid.org/0000-00033619-038X

Narjes Khosravi

Isfahan University of Medical Sciences

\section{Research Article}

Keywords: Anxiety, Depression, Family caregivers, Leukemia, Needs assessment, Stress

Posted Date: March 11th, 2021

DOl: https://doi.org/10.21203/rs.3.rs-219088/v1

License: (c) (i) This work is licensed under a Creative Commons Attribution 4.0 International License.

Read Full License 


\section{Abstract}

\section{Purpose}

The family of leukemia patients, due to their caring role, often feel psychological distress. This paper describes the efficacy of a designed family-need-based program on relieving depression, anxiety, and stress of family caregivers of leukemia patients by meeting the specific psychological needs of caregivers.

\section{Methods}

In this clinical trial, 64 family caregivers of leukemia patients referring to a medical center in Iran were recruited by convenience sampling and divided into study and control groups randomly. The study group attended a designed need-based program. The control group did not receive the intervention. Stress, anxiety, and depression before, right after, and one month after the intervention in family caregivers were compared using DASS-42. Data were analyzed using descriptive and inferential statistics; the significance level adopted was $5 \%$.

Results

Before the intervention, the mean score of depression, anxiety, and stress scale in both study and control groups showed no considerable difference $(P>0.05)$. After the intervention, the mean score of DASS-42 revealed a significant difference between the two groups and the study group did better on outcomes $(\mathrm{P}<$ $0.001)$.

\section{Conclusion}

This family-need-based program can decrease the level of stress, anxiety, and depression of the family caregivers of leukemia patients and may potentially alleviate the psychological distress of family caregivers over their caring role.

Trial registration number: IRCT2013093011895N2. Date of registration: 2014-05-06

\section{Introduction}

Family caregivers nowadays play a crucial role in caring for patients [1], whilst unlike professional caregivers, such as registered nurses, medical-surgical nurses, and psychiatric-mental health nurse practitioners, informal caregivers, generally family members or friends, provide a broad variety of support, such as psychological, physical, emotional, social and financial to individuals with a vast variety of medical conditions [2]. This scene is a simple illustration of the considerable psychological distress that family caregivers experience during leukemia treatment [3]. 
Evidence has shown that following a person is diagnosed with leukemia, the family of the patient senses significant psychological distress due to being in a state of emotional burden related to factors associated with stressors and demands that are difficult to cope with $[4,5]$. The study of Peterson, Chung, and Barrera (2020) has shown that stress, anxiety, and depression experienced by family caregivers of leukemia patients during their caring role are severe psychological distress that adversely affects the quality of the care provided by the family caregivers [6]. The Study of Segrin et al., (2018), furthermore, reported that acute stress, anxiety, and depression of family caregivers can have a damaging impact on the physical and mental health and well-being of both family caregivers and patients [7].

Extensive research has been conducted into identifying the health-care needs of family caregivers and the effects of the cancer diagnosis on patients' families [8, 9]; however, few experimental studies have been undertaken according to family caregivers' attitude and need, specifically and functionally to address the psychological distress experienced by the family caregivers of leukemia patients [10]. Regarded that whilst SEER data indicate very limited increase with time from 1975 to 2017 for all types of leukemias, and estimated new cases in 2020 in the USA were 60,530 all types with a moderate increase in ALL and AML from 1992 to 2017 [11], the annual new incidence rate for leukemia has been estimated to range from 0.1 to 1.5 per 100,000 individuals and the prevalence of this disease has been estimated to be 24 per 100,000 people over the world [12]. Thereupon a growing need for regular programs that, by carefully considering the set of requirements and ethical values of both caregivers and patients, relieve psychological distress of family caregivers of leukemia patients is increasingly obvious [13].

The researchers of the present study created this need-based program with the view to focusing on developing and implementing procedures to support clients according to their requirements [14]. We actively supported the need-based program by responsive instruction, decisive intervention, and direct and indirect support [15]. Researchers of the present study, therefore, carried out this randomized clinical trial to examine the efficacy of the designed family-need-based program on relieving depression, anxiety, and stress of family caregivers of leukemia patients by meeting the specific psychological needs of the caregivers.

\section{Methods}

\subsection{Study design}

This research study is conducted as a randomized clinical trial examining the efficacy of a designed family-need-based program on relieving depression, anxiety, and stress of family caregivers of leukemia patients by meeting the specific psychological needs of caregivers. The program involved three steps, comprising a preliminary phase of needs assessment, a step of education containing five training sessions, and a follow-up period. All steps were made respectively. The researchers carried out the research program through pretest and posttest in control and study groups in three stages.

\subsection{Study population and Sample size calculation}


The study population consisted of family caregivers of leukemia patients, involving ALL, AML, male, and female referring to Seyed Al Shohada University Hospital, Isfahan, Iran. A random sample was drawn according to inclusion criteria [16]. The sample size was calculated considering the objective of comparing two independent groups. The calculation was made considering the methodology of a sample calculation for a Pearson's Chi-square test. In this estimate, a $5 \%$ significance level, an $80 \%$ test power, a $0.30^{\circ}$ of freedom, and effect size were assumed, which can be considered a medium degree effect size [17]. The sample size obtained was 70 family caregivers of leukemia patients (35 per group). The software SPSS 20 was used.

\subsection{Recruitment and Randomization}

According to the inclusion criteria, people who referred to Sayed Al-Shohada Medical Center in Isfahan, Iran, who were the primary caregiver of a patient diagnosed with leukemia ( $A L L$ and AML) that means the family member who took the major responsibility of care for a leukemia patient and committed the largest proportion of time in the care for the patient, who were over 18 years old, who were able to communicate and comply with the rules of training sessions, who were just caring for one patient with leukemia refractory in the family, who were interested in participating in the study, who were able to speak, read, or write in Farsi, and who were not participating in other similar studies were chosen to join the study program. If the family caregiver did not attend more than two training sessions, had any issue that prevented them from taking care of the leukemia patient, or if the patient passed away, those caregivers were excluded from the study. Inclusion criteria related to patients were to be 18 or older, be in stage 0 of leukemia (ALL and AML), or higher, be diagnosed with leukemia over a month ago.

All of the family caregivers of leukemia patients admitted to the participating hospital during the survey period were invited to participate in this study. The personal data questionnaires were completed through face-to-face interviews in a private office in the hospital. The interviewers were four dedicated investigators recruited from research students in Isfahan University of Medical Sciences and trained before embarking on the survey. The interviewers identified 85 eligible family caregivers. Of these eligible family caregivers, 15 individuals expressed no interest and declined to participate. The participating family caregivers were encouraged to self-complete the questionnaires. But assistance from the interviewers was always available if necessary. For instance, if the respondent had a low visual acuity or another disability. The interviewers reviewed the returned questionnaires and asked the respondents to complete missing items if any. 70 questionnaires were included in randomization.

By the drawing method and using the table of random numbers, our research assistant who was responsible for conducting the education program divided the family caregivers into study and control groups, while the research team was blinded to randomization. Equally, 35 people were in the study and 35 people in the control group.

\subsection{Questionnaires}

In addition to questionnaires concerning personal data, embracing characteristics of the leukemia patients and their primary family caregivers, in this study, the Farsi version of the scale of depression, 
anxiety, and stress (DASS-42) was completed.

\subsubsection{The personal data questionnaire}

The personal data questionnaire included individual features of the patients and their family caregivers separately. The demographic information of the family caregiver was including sex, age, marital status, education level, employment, relation to the patient, and the duration of caring for the leukemia patient. The patients' features were including age, sex, marital status, education level, employment, and duration of being diagnosed with leukemia.

\subsubsection{The scale of depression, anxiety, and stress (DASS- 42)}

DASS-42 is a self-report questionnaire that measures depression, anxiety, and stress [18]. It was designed in 1997 and has been used repeatedly in different research programs [19]. DASS-42 is comprised of 42 items. Each item has three 14-item subscales scoring on the four-point Likert scale, ranging from zero (did not apply to me at all) to three (applied to me very much, or most of the time) [20]. Each subscale ranges from zero to 42 . Summing the items on each subscale calculates the overall score accordingly [21]. Scores above 20, 14, and 25 on the depression, anxiety, and stress subscales respectively are indicative of severe levels [22]. The Farsi version of DASS-42 has shown great scientific integrity and validity as well as consistency and reliability [23]. According to related studies, Cronbach's Alpha for depression, anxiety, and stress were $0.94,0.85$, and 0.87 , respectively for the Farsi version of the questionnaire [24]. Test-retest reliability coefficients, besides, were $0.80,0.89$, and 0.77 for depression, anxiety, and stress in the given order [25].

\subsection{Setting}

The researchers included one preliminary needs assessment step, one step of education comprising five training sessions, and one follow-up period in the study program. To do so, our responsible research assistant for setting up the educational intervention for family caregivers of leukemia patients, firstly, introduced herself to the participants. She fully explained the purpose of the study and the duration of the intervention and answered relevant questions. On the condition that the family caregiver was willing to participate in the program, they signed consent forms before the beginning of the intervention, then the program continued. Each step of the study program is discussed as follows:

\subsubsection{The first step: The preliminary phase of needs assessment}

The study program was started with a preliminary phase that was the needs assessment, which consisted of group discussions, interpretation, and compilation of all comments. This step started with field studies and then the investigators set up group discussions with the family caregivers of both study and control groups, patients of both groups, and specialists. To do so, ten 60-minute discussion sessions 
were held on 10 days. Each discussion session was held by 10 to 15 participants, including family caregivers, patients, specialists, and researchers. Participants were invited to attend any free discussion panel in accordance with their wishes. All participants attended the classes at least one time. The topic of all discussions was concentrated on overriding priorities and concerns of family caregivers about leukemia and patients [26]. Even though family caregivers were the central focus of this study program, in addition to family caregivers, health care professionals, and patients were interviewed to their expectations of family caregiving be assessed. The researchers tape-recorded and transcribed statements and then extracted key statements. The key terms were coded, and primary codes were grouped into the concepts. Measuring discrepancy between the current condition and wanted condition appropriately identified the family caregivers' paramount needs; based on the extracted concepts, the topic for each training session was outlined [27-30]. The specific requirements that were identified in this population of family caregivers during the preliminary phase of needs assessment and then addressed in the subsequent step are according to Table 1.

TABLE 1 The specific content of each training session of the family-need-based program for this population of family caregivers of leukemia patients based on the detailed needs assessment step

\begin{tabular}{|c|c|c|}
\hline Session & Assessed need & Title \\
\hline \multirow[t]{2}{*}{$\begin{array}{c}\text { First } \\
\text { session }\end{array}$} & $\begin{array}{c}\text { Lack of } \\
\text { information on }\end{array}$ & \multirow{2}{*}{$\begin{array}{l}\text { Objective: discuss the framework and rules of this group. } \\
\text { This session included these items: introducing family caregivers and researchers to each other, } \\
\text { setting plans and goals according to specific needs outlined in step one (needs assessment), } \\
\text { completing DASS- } 42 \text { for both study and control groups, answering related questions about } \\
\text { leukemia and the specific needs of leukemia patients and family caregivers. }\end{array}$} \\
\hline & $\begin{array}{l}\text { the specific } \\
\text { needs of family } \\
\text { caregivers and } \\
\text { leukemia } \\
\text { patients }\end{array}$ & \\
\hline $\begin{array}{l}\text { Second } \\
\text { session }\end{array}$ & $\begin{array}{l}\text { Standard } \\
\text { treatments for } \\
\text { leukemia } \\
\text {. Potential } \\
\text { complications } \\
\text { during and } \\
\text { after therapies }\end{array}$ & $\begin{array}{l}\text { Objective: describe potential weaknesses and strengths. } \\
\text { This session included: Over the previous session, exchanging information on different standard } \\
\text { treatments for leukemia, potential complications after therapies, and the importance of follow-up, } \\
\text { being in contact with the medical team, and considering the role of family caregivers in taking care } \\
\text { of leukemia patients. }\end{array}$ \\
\hline $\begin{array}{l}\text { Third } \\
\text { session }\end{array}$ & $\begin{array}{l}\text { ways of self- } \\
\text { care } \\
\text { management }\end{array}$ & $\begin{array}{l}\text { Objective: describe potential capabilities. } \\
\text { This session included: reviewing the two previous sessions' content, providing information about } \\
\text { the importance of self-care management for family caregivers and leukemia patients, and possible } \\
\text { ways of interaction between family and professional caregivers. }\end{array}$ \\
\hline $\begin{array}{l}\text { Fourth } \\
\text { session }\end{array}$ & $\begin{array}{l}\text {. Problem- } \\
\text { solving skills } \\
\text {. Techniques of } \\
\text { relieving } \\
\text { psychological } \\
\text { distress }\end{array}$ & $\begin{array}{l}\text { Objective: describe the ways to recognize and enhance ability. } \\
\text { This session included: reviewing the three previous sessions, acquiring information on problem- } \\
\text { solving skills and techniques of relieving psychological distress, including teaching relaxation } \\
\text { techniques for managing stress and anxiety at home. Explaining the importance of recognizing and } \\
\text { reporting symptoms of depression such as hopeless outlook, lost interest, increased fatigue, sleep } \\
\text { problems, irritability, changes in appetite and weight, uncontrollable emotions, and looking at } \\
\text { death, and also ways of managing them such as calling a local emergency number, avoiding social } \\
\text { isolation, removing anything that may cause harm, and listening but not judging. }{ }^{38}\end{array}$ \\
\hline $\begin{array}{l}\text { Fifth } \\
\text { session }\end{array}$ & $\begin{array}{l}\text { Identifying } \\
\text { misconceptions } \\
\text { about leukemia } \\
\text { patients, and } \\
\text { their effects on } \\
\text { emotional } \\
\text { modes }\end{array}$ & $\begin{array}{l}\text { Objective: Change the attention. } \\
\text { This session included these items: over the previous sessions, the interaction between family } \\
\text { caregivers and researchers, identifying misconceptions about leukemia patients, and their effects } \\
\text { on emotional modes, teaching the reassessment strategies. The participant family caregivers of } \\
\text { leukemia patients could listen to a guest preacher for spiritual fulfillment. CDs and booklets on the } \\
\text { concise overview of the course outline were presented to the study group participants. Immediately } \\
\text { after the fifth session, the DASS- } 42 \text { was completed for both study and control groups for the second } \\
\text { time. }\end{array}$ \\
\hline
\end{tabular}




\subsubsection{The second step: The training sessions}

The specific needs that were identified in the preliminary phase of the needs-assessment were summarized and fell into the specific-need categories. Objectives were entitled and the training-healthcare program was outlined for the study group. five 90-minute sessions during a month with eight to12 family members who took the primary responsibility for taking care of leukemia patients were held. Each training session was held on a separate day. We offered the same session over 5 days of the week and the next week we started the new next session and repeated the new session for 5 days and so forth (25 sessions in all). In this way, the timing of attending each session was in the order of personal preference of the family caregivers and they had the opportunity to choose the day when they would participate in the same session. Our research assistant used slide shows, images, pamphlets, and speeches in classes. Methods of questions and answers, role-playing, and lectures were adopted, and techniques of problemsolving, such as brainstorming, group discussion, and organizing small groups for sharing information were tried. The specific content of each training session of the family-need-based program is in Table 1.

\subsubsection{The third step: The follow-up period}

Within one month after the last session of the face-to-face training sessions, the family caregivers of leukemia patients of the study group were given advice based on their needs via telephone calls, and if needed, they were referred to the assistance unit or psychiatrist specialists. The average and range for the number of calls, duration of calls, and content of calls were on the family's needs and wishes as researchers were available.

The control group was supported by routine care plans and did not participate in the training sessions nor follow-up period.

\subsection{Data collection}

Data were collected in three stages, including before the first training session (before the second step), after the fifth training session (after the second step), and after the one-month follow-up (after the third step) by using personal data questionnaires and the DASS-42 questionnaire.

\subsection{Statistical methods}

To describe research results and analyzing and comparing baseline differences of personal data of participants, information summary methods in descriptive (frequency table, mean, mode, standard deviation, and calculating the percentage) and inferential statistics were used. To investigate the studied variables of the normal distribution, the Kolmogorov-Smirnov test was used. To investigate the homogeneity of control and study groups in terms of demographic characteristics, the independent statistical Chi-square test, Mann-Whitney test, and t-test were used.

As it was intended, the levels of depression, anxiety, and stress of family caregivers of leukemia patients were measured in three stages and compared two by two. Therefore, researchers used the paired t-test to determine if there is a significant difference between the means of the two independent groups. The 
repeated measures analysis of variance (ANOVA) also was used to compare the changes between groups. To compare the mean difference of depression, anxiety, and stress scores in control and study groups before and after the intervention, an independent t-test statistical method and paired t-test were used. To evaluate the relationship between individual features of participants and scores of DASS-42, one-way variance tests, independent and paired t-test were used. In all statistical tests, the level of significance was 0.05 . To calculate and analyze statistical information, version 20 of SPSS (Chicago, IL, USA) software was applied.

\section{Results}

At the end of the study program, 64 family caregivers, including 32 people in the study group and 32 people in the control group successfully finished the research course. Three study and three control group participants of the total were specifically dropped out of the study. The reporting participant flow diagram (CONSORT) showing the enrollment and dropout of participants is as Fig. 1.

The results from Chi-square, independent t-test, and Mann-Whitney test indicated that there was no statistically significant difference between the control and the study group in terms of individual characteristics $(P>0.05)$. The individual characteristics of the participants are indicated in Table 2 . 
Table 2

Individual features of family caregivers and patients

\begin{tabular}{|c|c|c|c|c|}
\hline \multirow[t]{2}{*}{$P>0.05$} & \multicolumn{2}{|c|}{ Family caregivers $(n=32))$} & \multicolumn{2}{|c|}{ Patients $(n=32)$} \\
\hline & Study & Control & Study & Control \\
\hline Age (years) & $(39.1 \pm 9.6)$ & $(40.3 \pm 12.1)$ & $(41.5 \pm 14.1)$ & $(43.4 \pm 17.07)$ \\
\hline $\begin{array}{l}\text { Length of care } \\
\text { (months) }\end{array}$ & $(6.1 \pm 3.8)$ & $(7.03 \pm 3.9)$ & - & - \\
\hline $\begin{array}{l}\text { Length of disease } \\
\text { (months) }\end{array}$ & - & - & $(6.1 \pm 3.8)$ & $(7.03 \pm 3.9)$ \\
\hline Gender & $\%$ & $\%$ & $\%$ & $\%$ \\
\hline Female & 71.9 & 61.4 & 43.8 & 34.4 \\
\hline Male & 28.1 & 40.6 & 56.2 & 65.6 \\
\hline \multicolumn{5}{|l|}{ Employment status } \\
\hline Working & 28.1 & 43.8 & 43.8 & 18.8 \\
\hline Jobless & 9.3 & 6.2 & 6.2 & 12.4 \\
\hline Homemaker & 56.4 & 50 & 34.4 & 50 \\
\hline Retired & 6.2 & 0 & 15.6 & 18.8 \\
\hline \multicolumn{5}{|l|}{ Marital status } \\
\hline Single & 6.2 & 15.6 & 30.9 & 31.75 \\
\hline Married & 87.5 & 78.1 & 62.9 & 55.85 \\
\hline Truce & 3.1 & 3.1 & 3.1 & 6.2 \\
\hline Deceased spouse & 3.2 & 3.2 & 3.1 & 6.2 \\
\hline \multicolumn{5}{|l|}{ Education level } \\
\hline Illiterate & 0 & 0 & 12.6 & 21.9 \\
\hline Primary school & 40.6 & 43.8 & 18.7 & 12.5 \\
\hline High school & 28.2 & 31.2 & 31.2 & 46.9 \\
\hline University & 31.2 & 25 & 37.5 & 18.7 \\
\hline \multicolumn{5}{|l|}{$\begin{array}{l}\text { Relation with } \\
\text { the patient }\end{array}$} \\
\hline Father & 6.2 & 6.2 & - & - \\
\hline
\end{tabular}




\begin{tabular}{|lllll|}
\hline P $>$ 0.05 & \multicolumn{3}{l|}{ Family caregivers $(n=32))$} & Patients $(n=32)$ \\
\cline { 2 - 5 } & Study & Control & Study & Control \\
\hline Mother & 9.4 & 21.9 & - & - \\
\hline Spouse & 50 & 25 & & - \\
\hline Children & 18.8 & 34.4 & - & - \\
\hline Other relatives & 15.6 & 12.5 & - & - \\
\hline
\end{tabular}

The results of the analysis of data showed that in the study group, the mean scores of the dependent variables (stress, anxiety, and depression) measured by DASS-42 gradually decreased in the three-time data collection, involving before the training sessions, right after the training sessions, and after the follow-up period. The paired t-test, moreover, indicated a significant difference between the mean scores of stress, anxiety, and depression before and right after the second step (the step of education), before the second step, and after the one-month follow-up (third step), and also right after the second step and after the follow-up period in the study group $(p<0.001)$ whereas in the control group, there was no significant change in the mean scores of the dependent variables $(P>0.05)$.

Results of the independent t-test showed that the changes in the mean scores right after the training sessions compared with the first data collection (before the training sessions that means before the second step) were significantly more in the study group than the control group $(p<0.001)$. This test also showed that the changes in the mean scores after the one-month regular follow-up period compared with the second data collecting (after the second step) were significantly more in the study group than the control group $(p<0.001)$.

Results of the repeated measures ANOVA revealed significant changes in the mean scores of anxiety, depression, and stress of the family caregivers of leukemia patients of the study group in three stages of pre-intervention, after the educational intervention, and after the follow-up period $(P<0.001)$. In comparison, no significant change was observed in the mean scores of the control group $(P>0.05)$. See Table 3. 
Table 3

Comparison of the mean scores of stress, anxiety, and depression before, right after, and one month after the training sessions in the groups of study and control

\begin{tabular}{|c|c|c|c|c|c|c|c|c|}
\hline \multirow[b]{2}{*}{ Variation } & \multicolumn{2}{|c|}{$\begin{array}{l}\text { Before the } \\
\text { training } \\
\text { sessions } \\
\text { Mean } \pm \text { SD }\end{array}$} & \multicolumn{2}{|c|}{$\begin{array}{l}\text { Immediately after the } \\
\text { training sessions Mean } \\
\pm \text { SD }\end{array}$} & \multicolumn{2}{|c|}{$\begin{array}{l}\text { After one-month } \\
\text { follow-up Mean } \pm \\
\text { SD }\end{array}$} & \multicolumn{2}{|c|}{$\begin{array}{l}\text { Within-subject }{ }^{\dagger} \\
\text { comparison (df } \\
=2 \text { ) }\end{array}$} \\
\hline & Study & Control & Study & Control & Study & Control & Study & Control \\
\hline Stress & $\begin{array}{l}31.16 \\
\pm 4.14\end{array}$ & $\begin{array}{l}31.09 \\
\pm 4.48\end{array}$ & $\begin{array}{l}15.21 \pm \\
5.19\end{array}$ & $\begin{array}{l}33.62 \pm \\
3.03\end{array}$ & $\begin{array}{l}10.56 \pm \\
3.37\end{array}$ & $\begin{array}{l}34.87 \pm \\
2.51\end{array}$ & $\begin{array}{l}P< \\
0.001\end{array}$ & $\begin{array}{l}P> \\
0.05\end{array}$ \\
\hline Anxiety & $\begin{array}{l}21.37 \\
\pm 6.31\end{array}$ & $\begin{array}{l}20.34 \\
\pm 6.56\end{array}$ & $\begin{array}{l}10.40 \pm \\
4.26\end{array}$ & $\begin{array}{l}22.71 \pm \\
5.08\end{array}$ & $\begin{array}{l}6.75 \pm \\
2.99\end{array}$ & $\begin{array}{l}23.65 \pm \\
4.96\end{array}$ & $\begin{array}{l}P< \\
0.001\end{array}$ & $\begin{array}{l}P> \\
0.05\end{array}$ \\
\hline Depression & $\begin{array}{l}27.56 \\
\pm 4.24\end{array}$ & $\begin{array}{l}28.78 \\
\pm 4.72\end{array}$ & $\begin{array}{l}12.64 \pm \\
4.61\end{array}$ & $\begin{array}{l}31.40 \pm \\
3.88\end{array}$ & $\begin{array}{l}7.37 \pm \\
2.76\end{array}$ & $\begin{array}{l}32.56 \pm \\
3.49\end{array}$ & $\begin{array}{l}P< \\
0.001\end{array}$ & $\begin{array}{l}P> \\
0.05\end{array}$ \\
\hline $\begin{array}{l}\text { Total } \\
\text { scores }\end{array}$ & $P>0.05$ & & $P<0.001$ & & $P<0.001$ & & $\begin{array}{l}P< \\
0.001\end{array}$ & $\begin{array}{l}P> \\
0.05\end{array}$ \\
\hline
\end{tabular}

The general trend of changes in the levels of stress, anxiety, and depression of two study and control groups of family caregivers obtained in the three stages of measurement, including the pretest, posttest, and after the follow-up period. This trend displayed a downward trend in the means of three items of stress, anxiety, and depression in the study group and a steady trend in the control group. See Fig. 2.

\section{Discussion}

The present randomized clinical trial was conducted to examine the efficacy of a designed family-needbased program on relieving depression, anxiety, and stress of family caregivers of leukemia patients by meeting the specific psychological needs of caregivers. The program consisted of needs assessment, education, and follow-up steps.

In this study, researchers based the educational intervention and peer support, including the educational workshops, support group, and follow-up assessments on the detailed needs assessment to address the specific needs of the family caregivers of leukemia patients. Accordingly, the results of the study of Quiñoa-Salanova et al., (2019) aiming at an understanding of the lived experience of the primary caregiver of a relative with multiple myeloma indicated that targeting psychological aspects of family caregivers' lives is hinged on the accurate assessment of the specific needs of family caregivers [31]. Akyar et al., (2019) in their study with the view to planning a palliative care model for adaptation of Turkish family caregivers of older individuals with cancer maintained needs assessment should be the first phase of planning for family caregivers of cancer patients [32]. Results of the study of Areia et al., 
(2020) also showed that needs assessment is an important part of the supportive intervention for family caregivers of patients with cancer [33]. Moreover, results of the study of Yan et al., (2020) aiming at identifying unmet supportive care needs and their relation to the quality of life of adult AL patients illustrate that healthcare professionals need to base their effective interventions on assessing the specific needs of clients [34].

According to our findings, at the end of the face-to-face training sessions, the levels of stress, anxiety, and depression in our study group were significantly lower than the control group who was supported by routine care plans, and did not participate in the training sessions. Similar results were found in the study by Toledano-Toledano et al., (2021). The mentioned authors identified the sociodemographic and psychosocial factors that predict resilience in family caregivers of children with cancer and mentioned face-to-face training as an important factor in the improvement of psychological distress of family caregivers [35]. Kang et al., (2021), furthermore, examined the impact of family caregivers' prognostic awareness on the quality of life and emotional state of both patients with advanced cancer and their caregiver. Their results showed that a face-to-face intervention which is based on the assessed needs had a significant impact on improving the symptoms of psychological distress in clients [36]. Our findings are consistent with the results of the study conducted by Sun and Qin (2021) who in their research maintained that face-to-face intervention can strongly support the mental health needs of family caregivers of cancer patients [37]. Accordingly, Shohani et al., (2018) carried out a study concerning comparing the effects of face-to-face and telenursing training methods on the quality of services provided by the family caregiver for patients with cancer. They reported both of these psychological interventions were effective in improving the mental health and relieving the psychological distress of family caregivers of patients with cancer [38].

The results of the present study have shown that, at the end of the follow-up period, the levels of stress, anxiety, and depression in the study group were significantly lower than the control group who was supported by routine care plans and did not participate in the follow-up period. Following our findings, the results of the Study of Kochaki Nejad et al., (2016) indicated the patient-caregiver education and followup program produces long-term results for the caregivers of patients with breast cancer compared to the routine care plans [39]. Furthermore, the study of Decadt et al., (2021) showed that proper nursing care and a follow-up program carried out for primary caregivers of oncology patients improved self-care and the quality of life for them and had long-term results [40]. Likewise, the results of the study of Ljungman et al., (2018) illustrated an individualized follow-up program produces long-term results for parents of children with cancer and these authors recommended considering face-to-face training and follow-up intervention as a part of the family caregiving program in health care centers [41].

\section{Study Limitations}

The present study had several limitations. First, due to the nature of the research, the volunteer participants participated in the study and filled out self-reported questionnaires, although this was unlikely to be seriously influenced by sample selection bias. Furthermore, psychological distress in family 
caregivers of leukemia patients could depend on several factors related to the patient's condition, such as cancer stage, age, and treatment status, as well as factors related to the family caregiver, such as financial difficulties, and family caregiver's access to support resources. Owning to the self-selection, variations in personal training patterns, and the patient's and the family's condition, the outcome of the study program could be influenced, although the researchers tried to minimize these effects by explaining them to the families.

\section{Conclusions}

The family caregivers of patients who are diagnosed with leukemia, as the result of having the specific role of caregiving, experience a high level of psychological distress. The present study illustrates that stress, anxiety, and depression of family caregivers of leukemia patients can be relieved if we design a regular need-based program based on the perceived specific psychological needs of family caregivers. Results suggest that developing such programs by using reliable and valid instruments can be a practical way to achieve this particular purpose. However, future studies should explore more factors related to patients as well as family caregivers that potentially underlie the psychological distress of the family caregivers of leukemia patients. Researchers, based on the study results, suggest conducting a research program with the view to assessing the effectiveness of a need-based program in relieving the psychological distress of family caregivers of leukemia patients and investigating its link with stress, anxiety, and depression of leukemia patients concerning underlying factors. We suggest healthcare workers explicitly consider specific needs and the risk of psychological distress of family caregivers as an important domain within holistic care programs and regard the necessity of designing such family-needbased programs for family caregivers and health services.

\section{Clinical Implications}

This study can illustrate a program for alleviating the psychological distress of family caregivers by accessing the urgent psychological needs of family caregivers of leukemia patients. The study program can introduce a model of tailored support and evidence-based practice to promote quality care. The study design can promote collaboration between experienced nurses and family caregivers.

\section{Declarations}

Funding This study has been funded by the research deputy of Isfahan University of Medical Sciences.

\section{Conflicts of interest None.}

Availability of data and material the data that support the findings of this study are available on request from the corresponding author. The data are not publicly available due to privacy or ethical restrictions.

Code availability the authors have full control of all primary data and allow the journal to review the code if requested 
Authors' contributions NK and MA should be considered joint first authors. NK involved in the conception, designing, and conducting the study, MA performed the data analysis, interpretation, wrote the manuscript and acted as the corresponding author.

Ethics approval This study was approved by the Ethics Committee of Isfahan University of Medical Sciences (Ethics No. 392057). This article is a part of the graduate thesis entitled "The effect of a family needs-based program on caregivers' burden of leukemia patients" in the field of psychiatric nursing registered in the database of clinical trials of Iran with the number of IRCT2013093011895N2.

Consent to participate All participants took part in the study after giving informed consent.

Consent for publication Freely-given, written informed consent was obtained from all participants.

Acknowledgments The authors appreciate the cooperation of officials and staff of the Sayed Al-Shohada (AS) Medical Center and also Mr. Saeed Pahlavanzade and Ms. Fariba Dalvi Isfahani, Department of Psychiatric Nursing, School of Nursing and Midwifery, Isfahan University of Medical Sciences. This work was supported by Isfahan University of Medical Sciences, Isfahan, Iran.

\section{References}

1. Shin JY, Steger MF, Shin DW, Kim SY, Yang HK, Cho J,... Park JH (2019) Patient-family communication mediates the relation between family hardiness and caregiver positivity: Exploring the moderating role of caregiver depression and anxiety. J Psychosoc Oncol 37(5):557-572. doi:10.1080/07347332.2019.1566808

2. Gu M, Hao X, Cong L, Sun J (2019) The prevalence, risk factors, and prognostic value of anxiety and depression in refractory or relapsed acute myeloid leukemia patients of North China. Medicine 98(50):e18196. https://doi.org/10.1097/MD.0000000000018196

3. Johansen S, Cvancarova M, Ruland C (2018) The Effect of Cancer Patients' and Their Family Caregivers' Physical and Emotional Symptoms on Caregiver Burden. Cancer Nurs 41(2):91-99. doi: $10.1097 /$ ncc. 0000000000000493

4. Naoki Y, Matsuda Y, Maeda I, Kamino H, Kozaki Y, Tokoro A,.. . Takada M (2018) Association between family satisfaction and caregiver burden in cancer patients receiving outreach palliative care at home. Palliat Support Care 16(3):260-268. doi:10.1017/s1478951517000232

5. Dionne-Odom JN, Currie ER, Johnston EE, Rosenberg AR (2019, December) Supporting family caregivers of adult and pediatric persons with leukemia. In Seminars in oncology nursing (Vol. 35, No. 6, p. 150954). WB Saunders

6. Peterson RK, Chung J, Barrera M (2020) Emotional symptoms and family functioning in caregivers of children with newly diagnosed leukemia/lymphomas and solid tumors: Short-term changes and related demographic factors. Pediatr Blood Cancer 67(2):e28059. doi:10.1002/PBC.28059 
7. Segrin C, Badger TA, Sikorskii A, Crane TE, Pace TWW (2018) A dyadic analysis of stress processes in Latinas with breast cancer and their family caregivers. Psychooncology 27(3):838-846. doi:10.1002/pon.4580

8. Wang C, Yan J, Chen J, Wang Y, Lin YC, Hu R, Wu Y (2020) Factors associated with quality of life of adult patients with acute leukemia and their family caregivers in China: a cross-sectional study. Health Qual Life Outcomes 18(1):8. https://doi.org/10.1186/s12955-020-1269-8

9. Rooeintan M, Khademi M, Toulabi T, Nabavi FH, Gorji M (2019) Explaining the postdischarge care needs of cancer patients: A qualitative study. Indian J Palliat Care 25(1):110

10. Sandén U, Nilsson F, Thulesius H, Hägglund M, Harrysson L (2019) Cancer, a relational disease exploring the needs of relatives to cancer patients. International journal of qualitative studies on health well-being 14(1):1622354

11. Kocjan E, Powell S (2019) Effectiveness of Art-Based Interventions for Reducing Stress among Caregivers of Cancer Patients. Occupational Therapy Graduate Student Evidenced-Based Research Reviews. 65.https://scholarworks.wmich.edu/ot_posters/65

12. Shah UA, Shah N, Qiao B, Acuna-Villaorduna A, Pradhan K, Adrianzen Herrera D, Sica RA, Shastri A, Mantzaris I, Derman O, Kornblum N, Braunschweig I, Ye BH, Verma A, Janakiram M (2020) Epidemiology and survival trend of adult T-cell leukemia/lymphoma in the United States. Cancer 126:567-574. doi:10.1002/cncr.32556

13. Owattanapanich W, Rujirachun P, Ungprasert P, Buaboonnam J, Techavichit P (2020) Prevalence and Clinical Outcome of Philadelphia-Like Acute Lymphoblastic Leukemia: Systematic Review and Metaanalysis. Clin Lymphoma Myeloma Leuk 20(1):e22-e29

14. Moghaddasi J, Taleghani F, Moafi A, Malekian A, Keshvari M, Ilkhani M (2018) Family interactions in childhood leukemia: an exploratory descriptive study. Support Care Cancer 26(12):4161-4168. doi:10.1007/s00520-018-4289-8

15. Davi F, Langerak AW, de Septenville AL, Kolijn PM, Hengeveld PJ, Chatzidimitriou A, ... Stamatopoulos $\mathrm{K}$ (2020) Immunoglobulin gene analysis in chronic lymphocytic leukemia in the era of nextgeneration sequencing. Leukemia, 1-7. https://doi.org/10.1038/s41375-020-0923-9

16. Ostgathe C, Wendt KN, Heckel M, Kurkowski S, Klein C, Krause SW, Fuchs FS, Bayer CM, Stiel S (2019) Identifying the need for specialized palliative care in adult cancer patients - development and validation of a screening procedure based on a proxy assessment by physicians and filter questions. BMC Cancer 19(1):646. https://doi.org/10.1186/s12885-019-5809-8

17. Gianfaldoni G, Mannelli F, Intermesoli T, Bencini S, Giupponi D, Farina G, Cutini I, Bonetti MI, Masciulli A, Bassan R (2020) Early peripheral clearance of leukemia-associated immunophenotypes in AML: centralized analysis of a randomized trial. Blood Adv 4(2):301-311. doi:https://doi.org/10.1182/bloodadvances.2019000406

18. Dehbi HM, Hackshaw A (2020) Sample size calculation in randomized phase Il selection trials using a margin of practical equivalence. Trials 21:301. https://doi.org/10.1186/s13063-020-04248-8 
19. Pouteau E, Kabir-Ahmadi M, Noah L, Mazur A, Dye L, Hellhammer J,.. . Dubray C (2018) The superiority of magnesium and vitamin B6 over magnesium alone on severe stress in healthy adults with low magnesemia: A randomized, single-blind clinical trial. PLoS ONE 13(12):e0208454. doi:10.1371/journal.pone.0208454

20. Mousavi S, Pahlavanzadeh S, Maghsoudi J (2019) Evaluating the Effect of a Need-based Program for Caregivers on the Stress, Anxiety, Depression, and the Burden of Care in Families of Children with Attention Deficit-hyperactive Disorder. Iran J Nurs Midwifery Res 24(2):96-101. doi:10.4103/ijnmr.IJNMR_11_17

21. Taylor AM, Thompson SV, Edwards CG, Musaad SMA, Khan NA, Holscher HD (2019) Associations among diet, the gastrointestinal microbiota, and negative emotional states in adults. Nutr Neurosci, 1-10. doi:10.1080/1028415x.2019.1582578

22. Malaysia KK (2019) Psychological morbidities amongst house officers in Sarawak General Hospital Kuching. Med J Malaysia 74(4):307

23. Allabadi H, Alkaiyat A, Alkhayyat A, Hammoudi A, Odeh H, Shtayeh J,.. . Haj-Yahia S (2019) Depression and anxiety symptoms in cardiac patients: a cross-sectional hospital-based study in a Palestinian population. BMC Public Health 19(1):232

24. Afzali A, Delavar A, Borjali A, MIRZAMANI M (2007) Psychometric properties of DASS-42 as assessed in a sample of Kermanshah High School students. Journal of Research in Behavioural Sciences, 5(2):81-92. URL: http://rbs.mui.ac.ir/article-1-123-en.html

25. Abshirini M, Siassi F, Koohdani F, Qorbani M, Mozaffari H, Aslani Z,.. . Sotoudeh G (2019) Dietary total antioxidant capacity is inversely associated with depression, anxiety, and some oxidative stress biomarkers in postmenopausal women: a cross-sectional study. Ann Gen Psychiatry 18:3. doi:10.1186/s12991-019-0225-7

26. Palmer-Wackerly AL, Krieger JL, Rhodes ND (2017) The role of health care provider and partner decisional support in patients' cancer treatment decision-making satisfaction. Journal of health communication 22(1):10-19

27. Khoshnood Z, Dehghan M, Iranmanesh S, Rayyani M (2019) Informational needs of patients with cancer: a qualitative content analysis. Asian Pacific journal of cancer prevention: APJCP 20(2):557. doi:10.31557/APJCP.2019.20.2.557

28. McEvoy B, Creaner M (2021) The experiences of mothers who have a child diagnosed with cancer. Psychol Health, 1-18. https://doi.org/10.1080/08870446.2021.1872791

29. Ai YT, Hu H, Yang CM, Zhou X, Yang XY, Ren HR, Huang YY (2021) Hindrances of peripherally inserted central catheter care of leukemia patients: a qualitative study. Support Care Cancer, 1-9. https://doi.org/10.1007/s00520-020-05941-9

30. Bryant AL, LeBlanc TW, Albrecht T, Chan YN, Richardson J, Foster M, ... Wujcik D (2020) Oral adherence in adults with acute myeloid leukemia (AML): results of a mixed-methods study. Support Care Cancer, 1-8. https://doi.org/10.1007/s00520-020-05349-5 
31. Quiñoa-Salanova C, Porta-Sales J, Monforte-Royo C, Edo-Gual M (2019) The experiences and needs of primary family caregivers of patients with multiple myeloma: A qualitative analysis. Palliat Med 33(5):500-509. https://doi.org/10.1177/0269216319830017

32. Akyar I, Dionne-Odom JN, Ozcan M, Bakitas MA (2019) Needs assessment for Turkish family caregivers of older persons with cancer: first-phase results of adapting an early palliative care model. J Palliat Med 22(9):1065-1074

33. Areia NP, Góngora JN, Major S, Oliveira VD, Relvas AP (2020) Support interventions for families of people with terminal cancer in palliative care. Palliative Supportive Care Feb:1-9.

DOI:10.1017/s1478951520000127

34. Yan J, Wang Y, Chen J, Wang C, Lin Y, Hu R, Wu Y (2020) Unmet supportive care needs and its relation to quality of life among adult acute leukemia patients in China: a cross-sectional study. doi.org/10.21203/rs.3.rs-15955/v1

35. Toledano-Toledano F, Luna D, Moral de la Rubia J, Martínez Valverde S, Bermúdez Morón CA, Salazar García M, Vasquez Pauca MJ (2021) Psychosocial Factors Predicting Resilience in Family Caregivers of Children with Cancer: A Cross-Sectional Study. International Journal of Environmental Research Public Health 18(2):748. https://doi.org/10.3390/ijerph18020748

36. Kang E, Keam B, Lee NR, Kang JH, Kim YJ, Shim HJ, ... Yun YH (2021) Impact of family caregivers' awareness of the prognosis on their quality of life/depression and those of patients with advanced cancer: a prospective cohort study. Support Care Cancer 29(1):397-407. https://doi.org/10.1007/s00520-020-05489-8

37. Sun H, Qin Y, Hengudomsub P (2021) Factors associated with resilience in spousal caregivers of patients with cancer: An integrative review. Nursing Open

38. Shohani M, Mozafari M, Khorshidi A, Lotfi S (2018) Comparing the effects of face-to-face and telenursing education on the quality of family caregivers caring in patients with cancer. Journal of family medicine primary care 7(6):1209-1215. https://doi.org/10.4103/jfmpc.jfmpc_317_18

39. Kochaki Nejad Z, Mohajjel Aghdam A, Hassankhani H, Sanaat Z (2016) The Effects of a PatientCaregiver Education and Follow-Up Program on the Breast Cancer Caregiver Strain Index. Iran Red Crescent Med J 18(3):e21627. doi:10.5812/ircmj.21627

40. Decadt I, Laenen A, Celus J, Geyskens S, Vansteenlandt H, Coolbrandt A (2021) Caregiver distress and quality of life in primary caregivers of oncology patients in active treatment and follow-up. European Journal of Cancer Care. https://doi.org/10.1111/ecc.13399

41. Ljungman L, Cornwall M, Ghaderi A, Ljungman G, von Essen L, Ljótsson B (2018) An open trial of individualized face-to-face cognitive behavior therapy for psychological distress in parents of children after the end of treatment for childhood cancer including a cognitive-behavioral conceptualization. PeerJ 6:e4570. ttps://doi.org/10.7717/peerj.4570

\section{Figures}




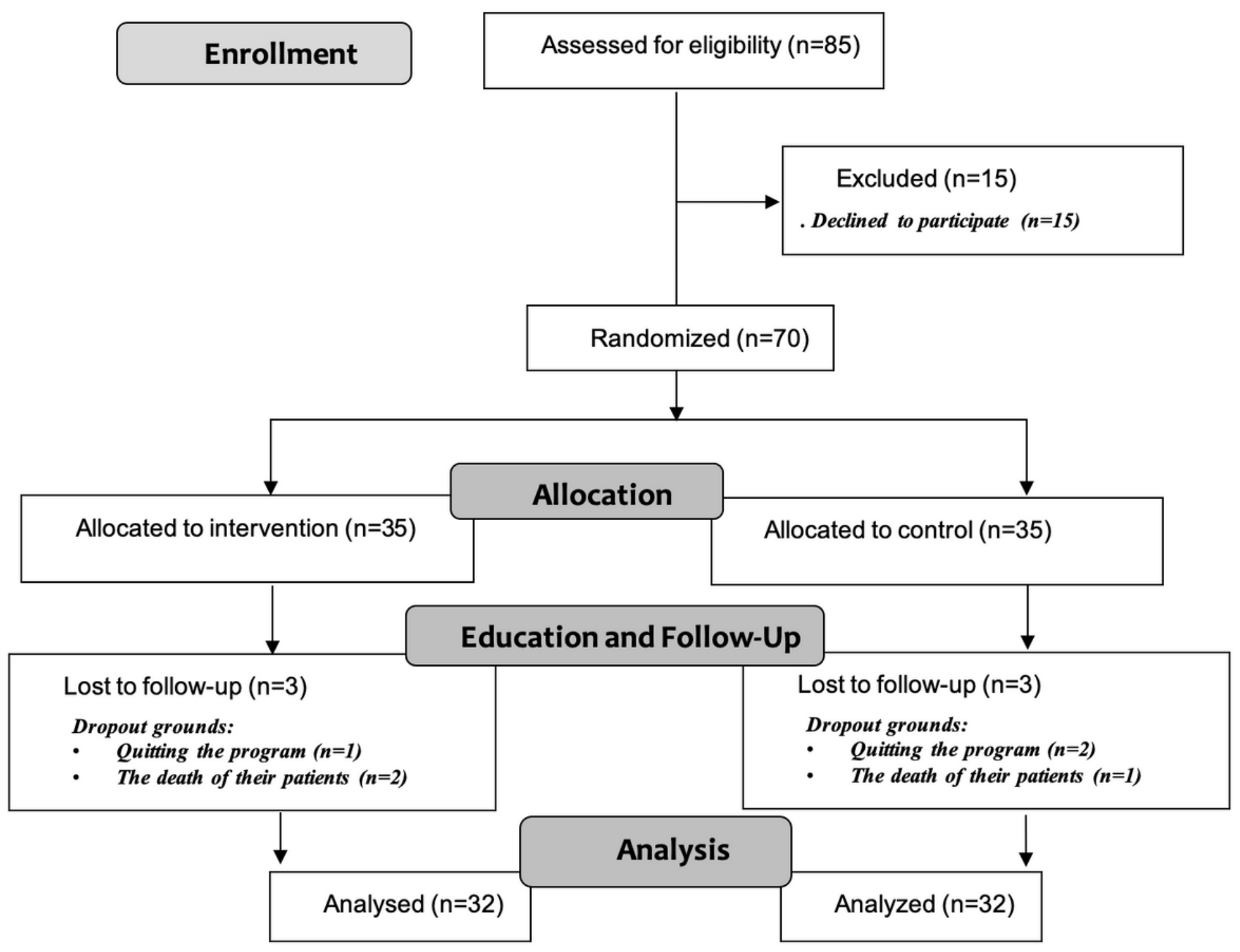

Figure 1

Reporting participant flow diagram (CONSORT) showing the enrollment and dropout of participants during the randomized clinical trial

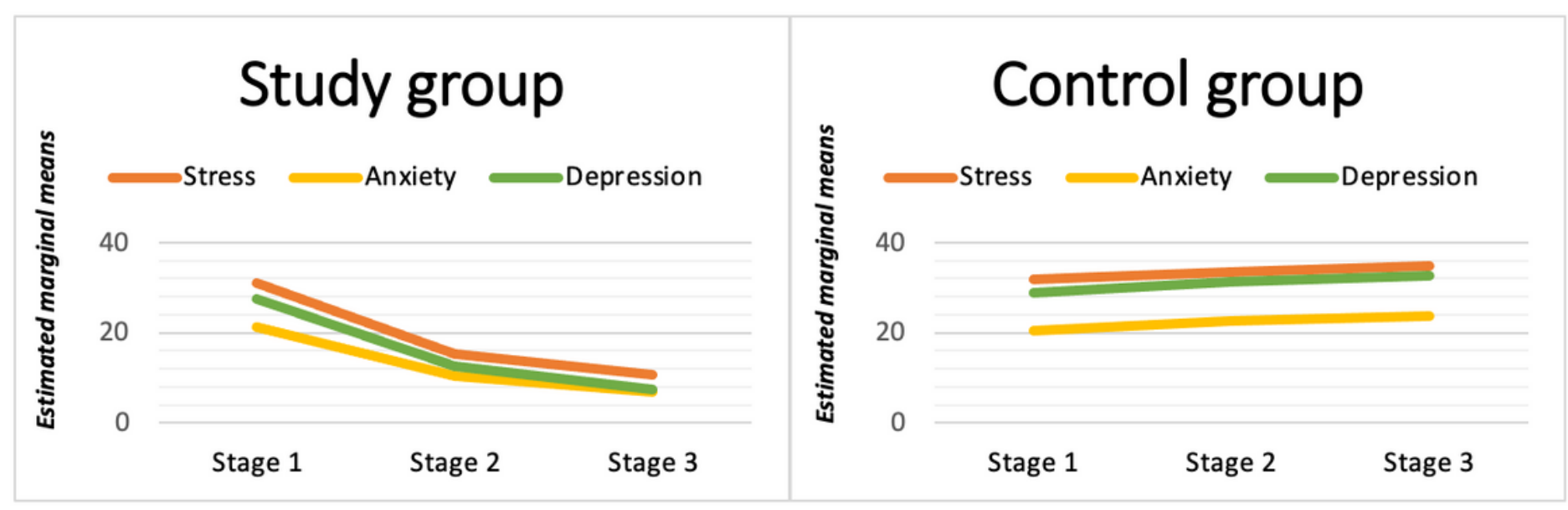

Figure 2 
The trend of changes in the stress, anxiety, and depression scores obtained in the three stages of measurement, including the pretest, posttest, and after follow-up in study and control groups

\section{Supplementary Files}

This is a list of supplementary files associated with this preprint. Click to download.

- CONSORT.doc 